\title{
ABDOMINAL TUMOURS IN INFANTS AND CHILDREN*
}

\author{
BY

\section{EVERETT KOOP} \\ From the Surgical Clinic of the Children's Hospital of Philadelphia and the Harrison Department of Surgical Research, \\ University of Pennsylvania School of Medicine
}

If abdominal tumours in children were symptomatic more often than they are, diagnosis would be simple and indications for management clear. However, abdominal tumours are usually silent. Frequently they are discovered accidentally. They may well be diagnosed by chance in the systematic work-up for apparently unrelated symptoms, as, for example, in a child with a fever of unknown origin who has dullness to percussion at his left base on physical examination and in whom a chest film reveals not pneumonia but a retroperitoneal tumour.

When one speaks about abdominal tumours in children two major tumours come to mind, the embryoma of the kidney or Wilms' tumour and the neuroblastoma. These two tumours are thought of almost to the exclusion of others and perhaps rightly so. They are not only the most usual and the most dangerous to life, but are also amenable to treatment, if happily the diagnosis is made early.

Long experience with these killers of children leads one to a philosophy of tumour management. In America, at least, cancer is the No. 2 killer of children, exceeded only by accidents. Probably the same is more or less true in Britain although you do not seem to lead the frantic lives that we do and perhaps cancer is even more important as a cause of paediatric death than are accidents.

It is our firm belief that abdominal tumours present an urgency, if not an emergency situation in management. Several valid reasons might be cited in support of this belief but, for the sake of a teaching point, the naive explanation that we give is that in every tumour, such as Wilms', there is a day when metastases take place. Before this day extirpation of the primary tumour should result in a complete cure. After this day extirpation of the tumour has no effect on mortality and in all likelihood even the addition of X-ray therapy and chemotherapy to the surgeon's armamentarium probably alters the prognosis but little.

Another keystone in the management of abdominal

* Lecture delivered at the University of Liverpool in June, 1959. tumours lies in ordering minimal investigations, not only because more are unnecessary, but also because the longer a child lies about the wards of the hospital, the more opportunity he has for his abdomen to be palpated by enthusiastic members of the house staff and by medical students.

The third point in our philosophical management of tumours is minimal trauma by palpation, whether this be pre-operatively or at the operating table. We attempt ligation of the blood supply to the tumour before handling it, if at all possible. This philosophy leads us to place an adhesive sign on the abdominal skin which says, 'Do not palpate this abdomen' as soon as we have made the diagnosis of an intra-abdominal mass, and commonly leads us to wide incisions of the thoraco-abdominal variety in order to approach an intra-abdominal or retroperitoneal mass without undue manipulation.

The differential diagnosis of intra-abdominal tumours is certainly important, even though the tumour must come out, because of differences in the life history of these two major malignant lesions, the Wilms' tumour and the neuroblastoma, and operative management dictated by these differences. The Wilms' tumour has a capsule and, if this is ruptured spontaneously or during the operative procedure, the prognosis is tantamount to eventual death. The pattern of metastases is to the lung fields and seldom to the regional nodes. The mortality is high, the best results being obtained in those clinics where the aforementioned philosophy is carried out and where prompt surgery is followed by adequate irradiation.

The neuroblastoma, on the other hand, is frequently non-encapsulated; its metastatic pattern is to the bones of the extremities, to the skull and retro-orbital areas. Growth by direct extension into adjacent organs is common, and the best mortality is not necessarily reported from those clinics that treat neuroblastomas as they do Wilms' tumours by $X$-ray treatment immediately after surgery. This tumour apparently has a unique ability to revert from a malignant to a benign form. Although we realize that little or nothing in the way 
of therapy may be associated with this course of events, our own experience leads us to believe that the best results have been in those patients who had a major surgical insult to their tumour.

The intravenous pyelogram is at all odds the key study in the differential diagnosis of these two tumours. Some of the films shown here are far superior to others insofar as visualization of the kidney is concerned. The reasons for this include not only a better dye substance being available today, but also the technique currently in use for giving the patient a carbonated beverage to drink immediately after injecting the dye intravenously in order that the carbon dioxide liberated from the beverage will fill the stomach, push the viscera out of the way, and show the dye secreted by the kidney through a large radiolucent gastric shadow of gas. Furthermore, we now reinforce the intravenous dose of dye by a second injection if there is no apparent dye secretion in the first film taken five minutes after the initial injection. Perhaps a review of some of the problems presented by patients may serve to illustrate both the commonplace and the bizarre.

\section{Case Reports}

Case 1. M.B. This $1 \frac{1}{2}$-year-old boy had been chronically ill for four months with weight loss, fever and diarrhoea. Physical examination revealed dullness at the right lower base of the lung field posteriorly. The liver was palpable $3 \mathrm{~cm}$. below the costal margin and the spleen was enlarged. The preliminary film of his abdomen showed a huge mass in the right upper quadrant with amorphous calcification. The intravenous urogram showed a typical displacement of the right kidney by a suprarenal mass. This is the usual textbook picture of a suprarenal neuroblastoma. It is classical in the position of the tumour, the displacement of the pelvi-caliceal system of the kidney and in the appearance of the calcium (Fig. 1).

Case 2. D.C. A $3 \frac{1}{2}$-year-old boy had a three to fourweek history of intermittent fever, abdominal pain, leg pain, sore joints, weakness and weight loss. The diagnosis of rheumatic fever was considered before admission to hospital. In hospital a physical examination revealed a mass in the left upper quadrant and an intravenous urogram indicated in the five-minute film displacement of the ureter both in the anterior-posterior and oblique projections. Calcium was also seen in this lesion. It soon becomes apparent that the neuroblastoma can appear anywhere from the cervical region to the coccyx. The calcium pattern varies and is not $100 \%$ reliable. Here the tumour is not in the typical suprarenal position but is below the kidney (Fig. 2).

Case 3. E.B. A 23-month-old boy had intermittent episodes of diarrhoea for one year. More recently he had had an anaemia which had not responded to iron medication but he had not experienced fever or weight loss. On physical examination a palpable abdominal mass was found in the left flank. Intravenous urography revealed a displacement of the left ureter medially and anteriorly by a retroperitoneal mass lesion containing no calcium. This also proved to be a neuroblastoma (Fig. 3).

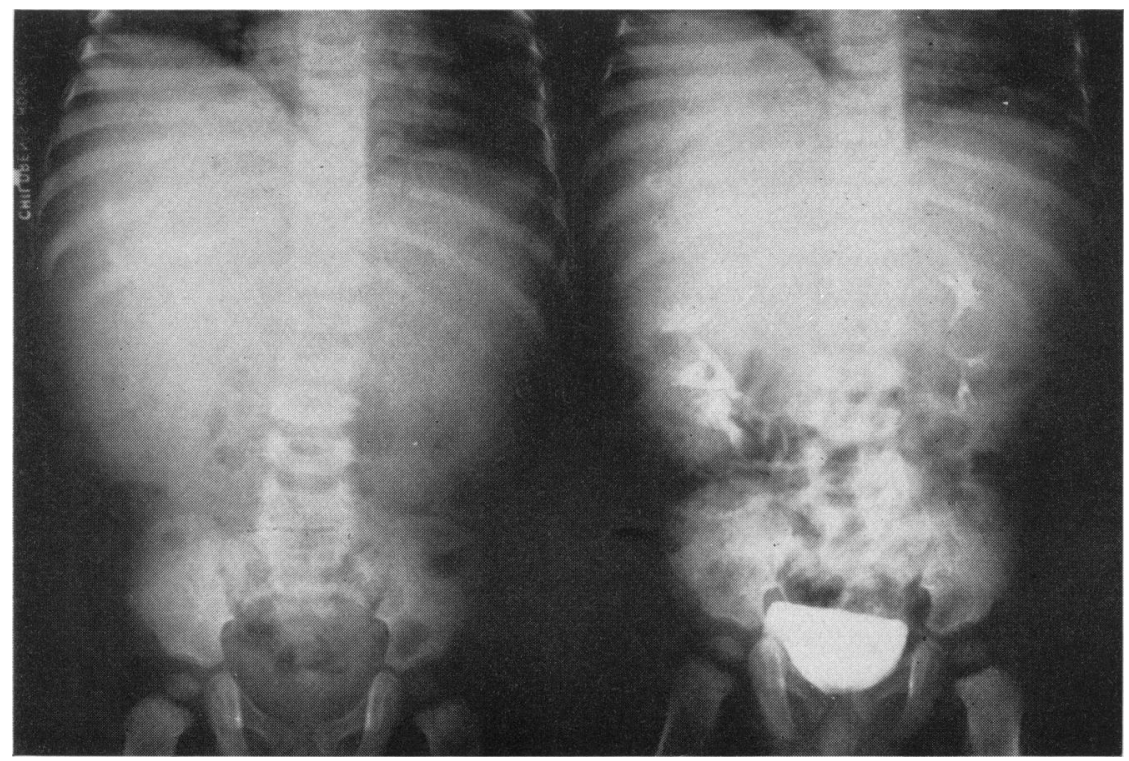

Fig. 1.-Case 1. Typical displacement of right kidney by a suprarenal neuroblastoma. Note calcific shadows. 


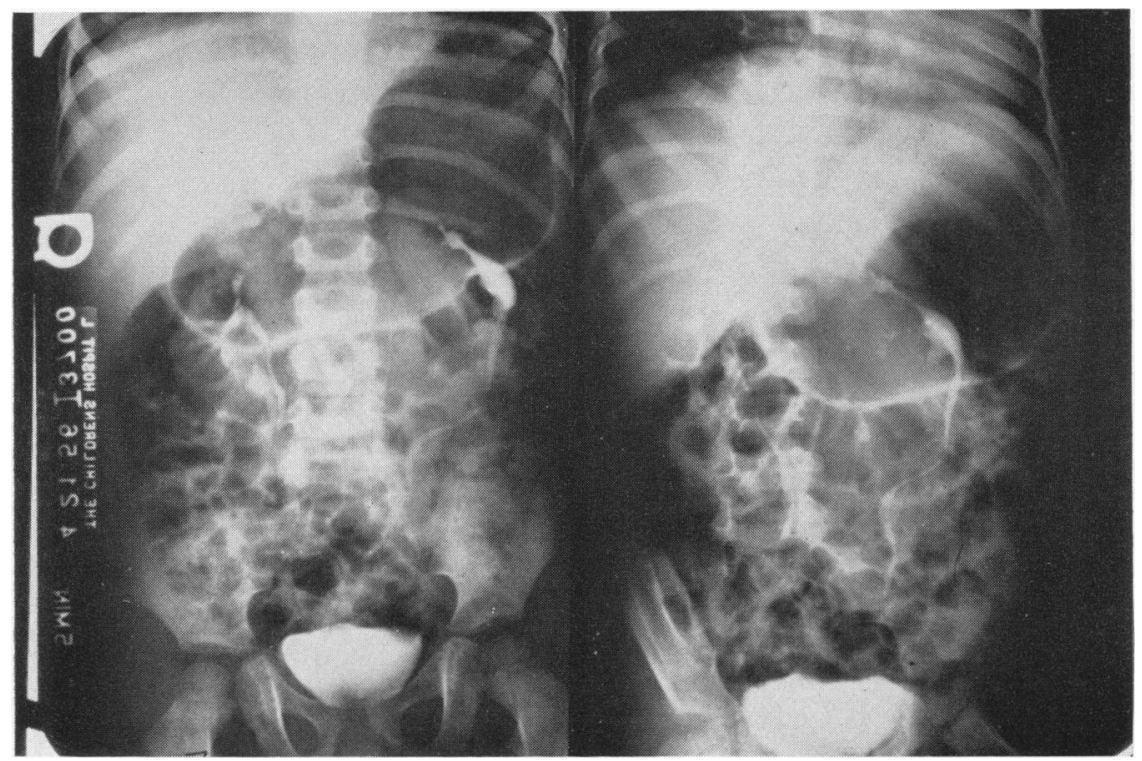

Fig. 2.-Case 2. Neuroblastoma. Left upper quadrant mass with displacement of ureter and kidney by infrarenal mass.

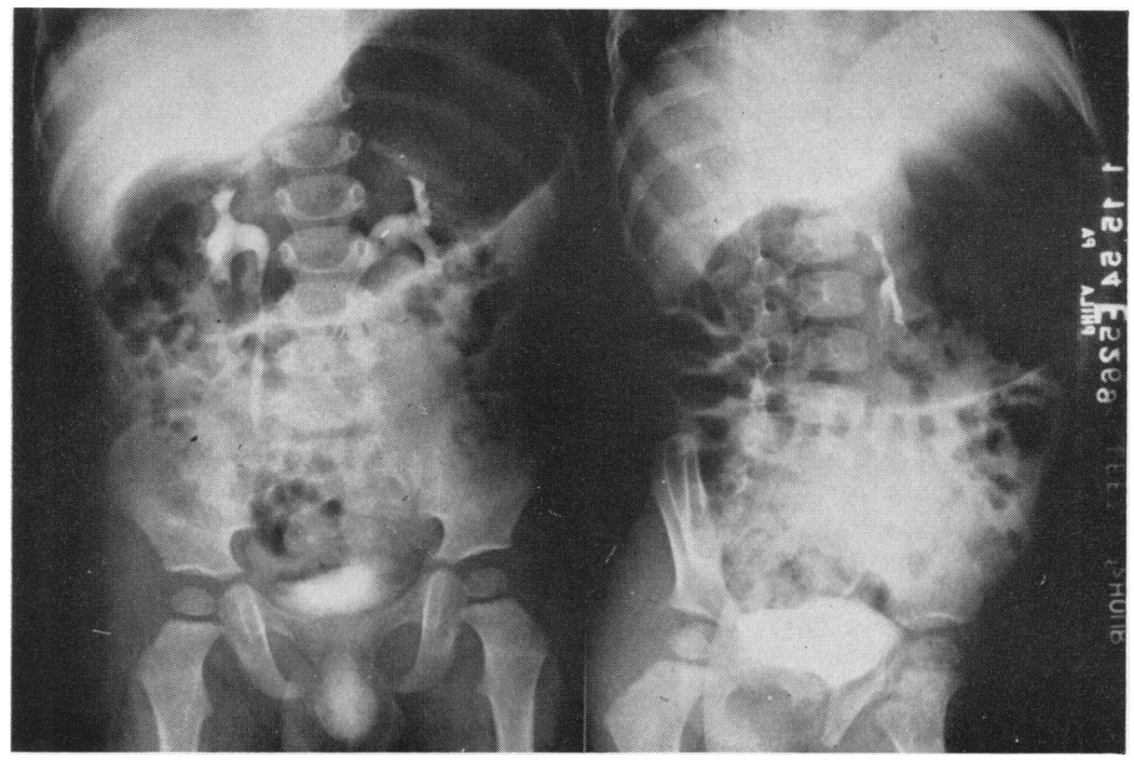

Fig. 3.-Case 3. Neuroblastoma. Left ureter displaced medially and anteriorly. No calcium. 


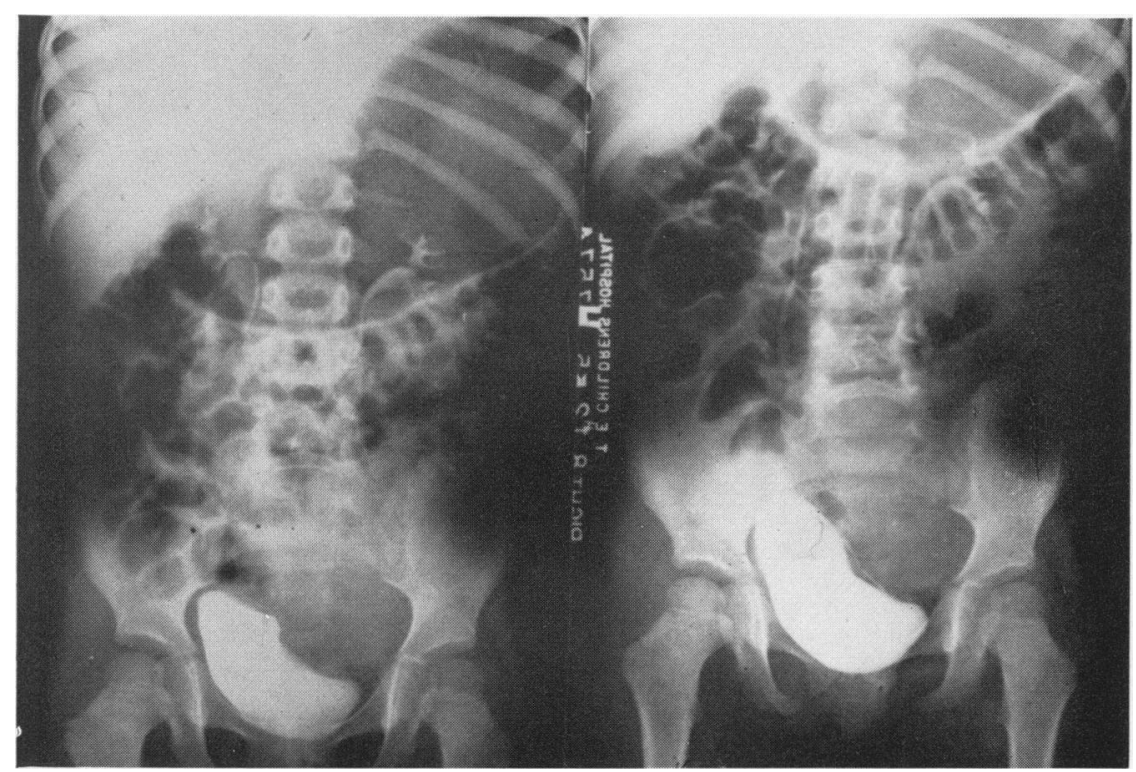

FIG. 4.-Case 4. Neuroblastoma. Mass indenting bladder and displacing ureter far laterally. Excellent demonstration of benefit derived from gas shadow in stomach produced by carbonated beverage.

Following extirpation of the tumour the child is alive and well four years post-operatively.

Case 4. S.C. A $3 \frac{1}{2}$-year-old girl had had poliomyelitis at the age of 4 months. One year before admission she began to complain of pain in her left leg and had numerous hospital admissions, all of which resulted in the assessment of her pain as a result of her poliomyelitis. By the time she reached the Children's Hospital of Philadelphia, the diagnosis was easy because there was a large mass not only palpable but also visible in her left lower quadrant. An intravenous pyelogram showed a mass indenting the bladder and displacing the ureter far laterally. This also proved to be neuroblastoma. The patient died six months later. The kidney is not displaced in any way in these films which show remarkably well the advantages of giving a carbonated drink in association with intravenous pyelography (Fig. 4).

Case 5. M.B. was a 5-year-old boy who entered the hospital with a four-month history of intermittent fever, pains in the joints, neck and head. At another hospital three months previously his long bones, intravenous pyelogram and skull films were all reported as being negative. By exclusion a diagnosis of Still's disease was made and he was placed on cortisone therapy. On this treatment he improved for a while but by the time of admission to the Children's Hospital of Philadelphia his pain had returned and his headaches were a primary symptom. Skull films showed evidence of increased intracranial pressure and a ventriculogram taken eight days later showed no mass lesion. A long bone survey done at the same time showed evidence of metastatic disease. Intravenous pyelography five days after the air study revealed a neuroblastoma on the right side (Fig. 5). Everything about this patient was carried out in backward fashion. Diagnosis at the primary site was made only after metastases had appeared.

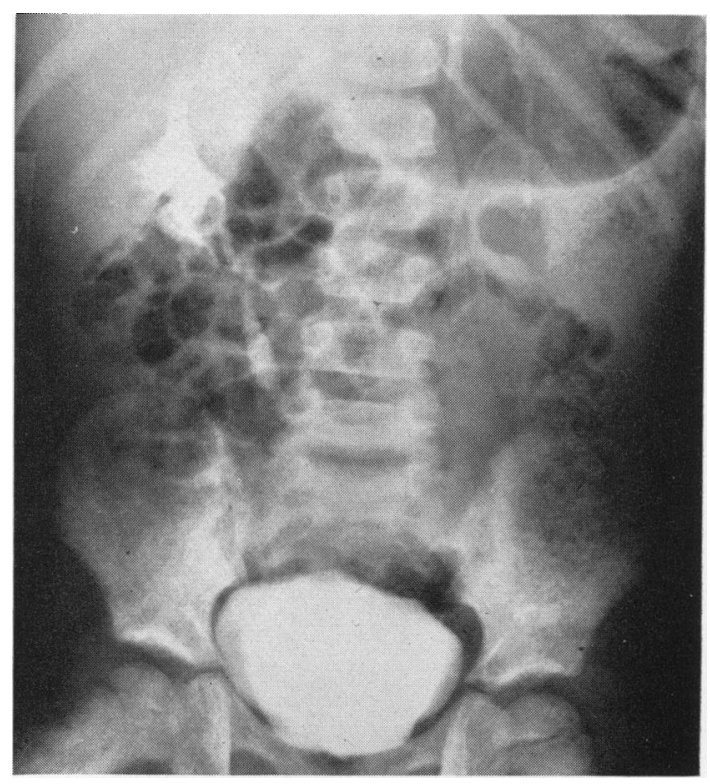

Fig. 5.-Case 5. Neuroblastoma on right. Diagnosis made only after metastases produced increased intracranial pressure 
In summary, concerning neuroblastomas, you have seen a textbook picture of the suprarenal position of a neuroblastoma above the kidney and a variation of the neuroblastoma below the kidney. One tumour displaced the ureter anteriorly and medially while still another displaced the ureter laterally and indented the bladder. Calcium was present in some but not in all flat films.

The histories of these patients included weight loss, pain, fever of unknown origin, diarrhoea and anaemia. In so far as similar syndromes are concerned, neuroblastoma mimicked poliomyelitis, arthritis and rheumatic fever. Such are the vagaries of the neuroblastoma.

One of our residents married one of our nurses and in the course of time produced a child. By this time the young physician had moved to another city in the course of his training and when the child was born with an abdominal mass, the mass was assumed to be spleen because of a Rhesus incompatibility on the part of the parents. The mother took her baby into a rural area of Pennsylvania where the local physician watched the mass grow in size until it reached the umbilicus, whereupon the infant was referred to one of our medical confrères for evaluation of splenomegaly. It was obvious on examination of the abdomen that the mass in question was a retroperitoneal tumour and not spleen, and following the philosophy of management already outlined and spurred on additionally by the fact that the parents of the patient were our friends, the child was operated upon about six hours after admission to hospital. The tumour was a neuroblastoma and not only inoperable in the usual sense of the word by being wrapped around the hilum of both kidneys, but there were many metastases, multiple and small, covering the entire surface of the liver. Biopsy of both the primary and metastatic lesions showed an immature variety of neuroblastoma. Because of the helpless feeling of operating upon an impossible situation in a child of a friend, we attempted to scoop out what tumour we could, actually used very bad cancer surgical technique, and advised no X-ray therapy because we thought the child would not benefit from it and that the sooner he died the better for all concerned. Two weeks later his subcutaneous tissue was the site of multiple nodules such as one sees in a terminal leukaemia. To make a long story short, 13 years have gone by and this child is alive and well, has no abdominal tumour, even when his abdomen is palpated under anaesthesia, and his intravenous pyelogram shows no major abnormality. It was this patient and his subsequent course that led us to withhold radiation therapy in a neuroblastoma post- operatively and, in a sense, we have built up a control series with surgery and no X-ray or chemotherapy, the mortality of which compares favourably with any series reported from our country in each of which X-ray therapy is given a major share of the credit for what survival there is.

In 1955 I reported a survival of $30.8 \%$ in the surgical management of neuroblastoma, that is 12 survivals of 44 patients. After presentation of this experience to several groups, the consensus was that if I had irradiated the patients as well I would have had an even better survival rate and, therefore, we planned a series of surgery followed by radiation. The next eight patients died following radiation and although eight is not a large number, it is a sufficiently large number for the surgeon to assess and perhaps change his tactics. When we reviewed the situation in 1958 we found that all the patients reported alive in 1955 were still alive in 1958 and one reported to be dead in 1955 (due to faulty follow-up) was indeed alive in 1958, and our survival was not $30.8 \%$ but $33.3 \%$ with a follow-up of 4 years 2 months minimum and 12 years maximum. Since reverting in early 1958 to the surgical extirpation of neuroblastomas without the benefit of radiation therapy, we again have several patients who seem on their way to the closest thing to a cure that one can talk about in the treatment of malignant disease in children.

The following are some examples of embryoma of the kidney.

Case 6. A $2 \frac{1}{2}$-year-old boy had an asymptomatic left upper quadrant mass found on routine physical examination by his paediatrician. An intravenous pyelogram showed a typical Wilms' tumour. The boy was immediately operated upon and treated with irradiation but metastases appeared in the liver and lung fields. The child died approximately one year after the appearance of metastases. In this instance the intravenous pyelogram revealed the usual garbled shadow produced by the dye in a Wilms' tumour (Fig. 6). In spite of the fact that this tumour was small, it metastasized early.

Case 7. R.K. This 7-month-old girl entered hospital because her mother had felt a huge abdominal mass while giving the child a bath. The mother, a competent observer, claimed that the tumour was not present the day before and the presumption is that haemorrhage into the tumour produced a change in size which led to its palpation. An intravenous urogram was done and this study revealed an intrinsic tumour in the left kidney (Fig. 7). The mass was removed and the child was given 2,500 $R$ tissue dose to the midline. Seven years later she is alive and well with no evidence of metastases. Here, a huge tumour treated in the same way as in the previous patient showed no evidence of metastasis and has a seven-year cure. 


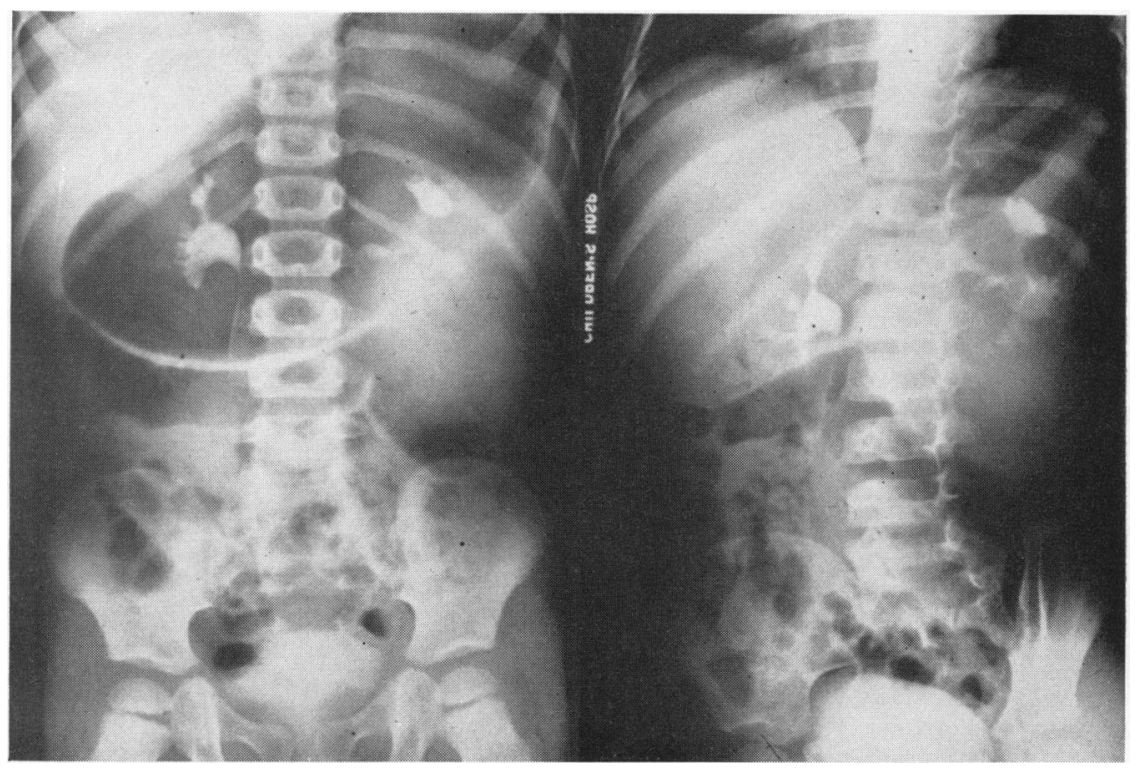

Fig. 6.-Case 6. Small Wilms' tumour with early metastasis.

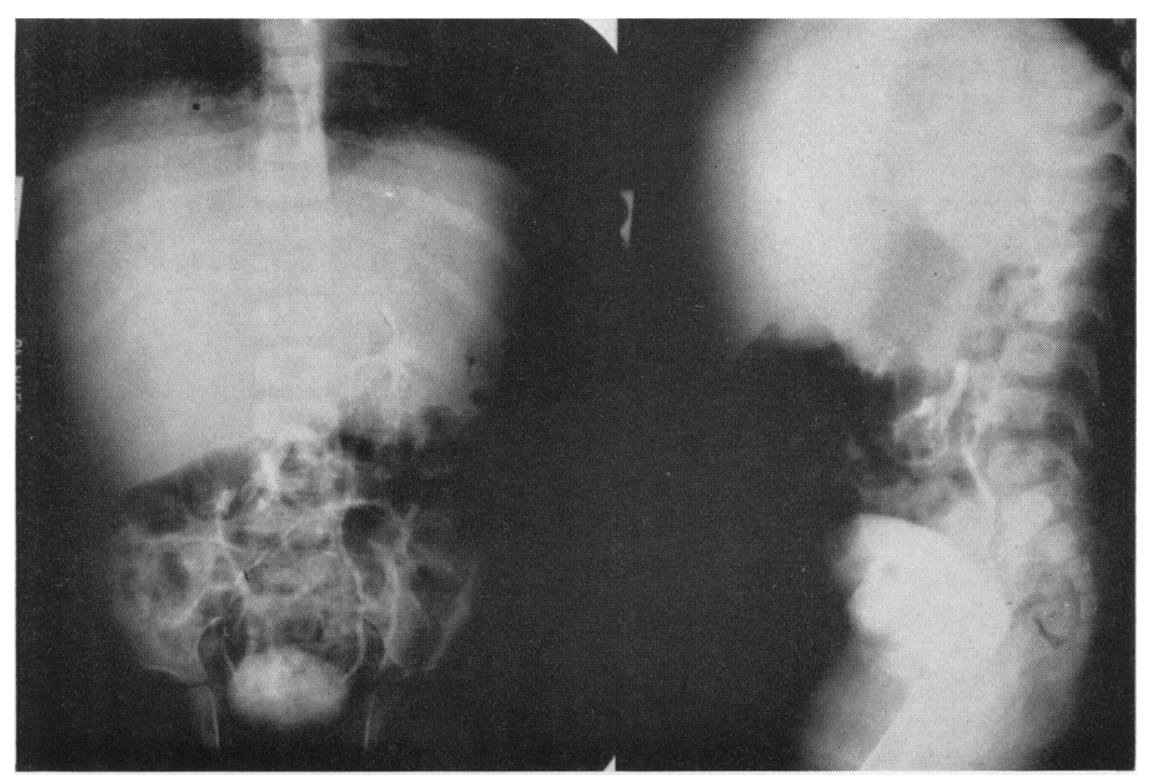

FIG 7.-Case 7. Huge Wilms' tumour without metastases; seven-year survival. 
Case 8. W.W. This 3-year-old boy went to see his family doctor for a routine prophylactic injection one week before admission. The physician, an unusually thorough gentleman, quickly palpated the abdomen as part of a routine check-up and felt the abdominal mass. Intravenous pyelography revealed a typical distorted and garbled opaque shadow indicating an intrinsic mass in the kidney (Fig. 8). The boy is alive and well eight years after surgery and X-ray therapy.

Case 9. E.Y. was a 1-year-old girl, who two weeks before admission was found by her father to have a mass on the right side. During the intervening two weeks her right side had become firm and rigid. Laxatives and enemas had been given in an attempt to remove what her father suspected was a faecal impaction. After surgery the patient developed metastases and died rather promptly. The anterior-posterior view in this child is not helpful. A lateral film was needed for a differential diagnosis between a neuroblastoma and a Wilms' tumour (Fig. 9).

Case 10. S.O. This 11-month-old girl was sent into hospital because someone thought he felt a mass in the left upper quadrant. At our institution no mass could be felt but intravenous pyelography was undertaken to rule out any doubt. This showed a very minimal distortion of the left renal pelvis. Our best films on this child are not available, but Fig. 10 indicates the area in which we were concerned. It was decided to do a nephrectomy rather than cut into the tumour, if such were present, for diagnosis, and when the kidney was removed it looked like a normal organ. When it was sectioned, however, there was a $2 \mathrm{~cm}$. nodule just beneath

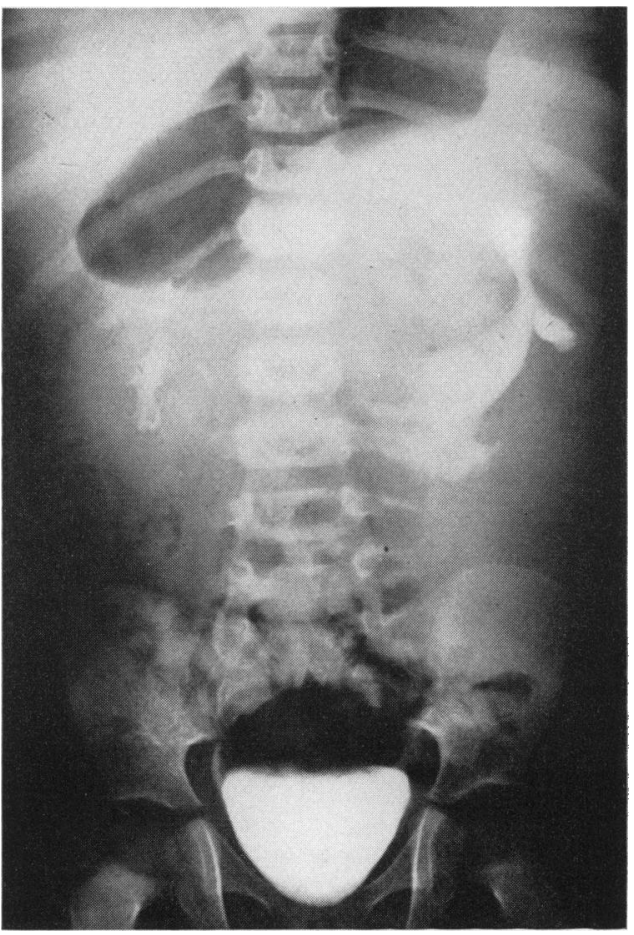

Fig. 8.-Case 8. Typically distorted pelvis by Wilms' tumour; eight-year survival.

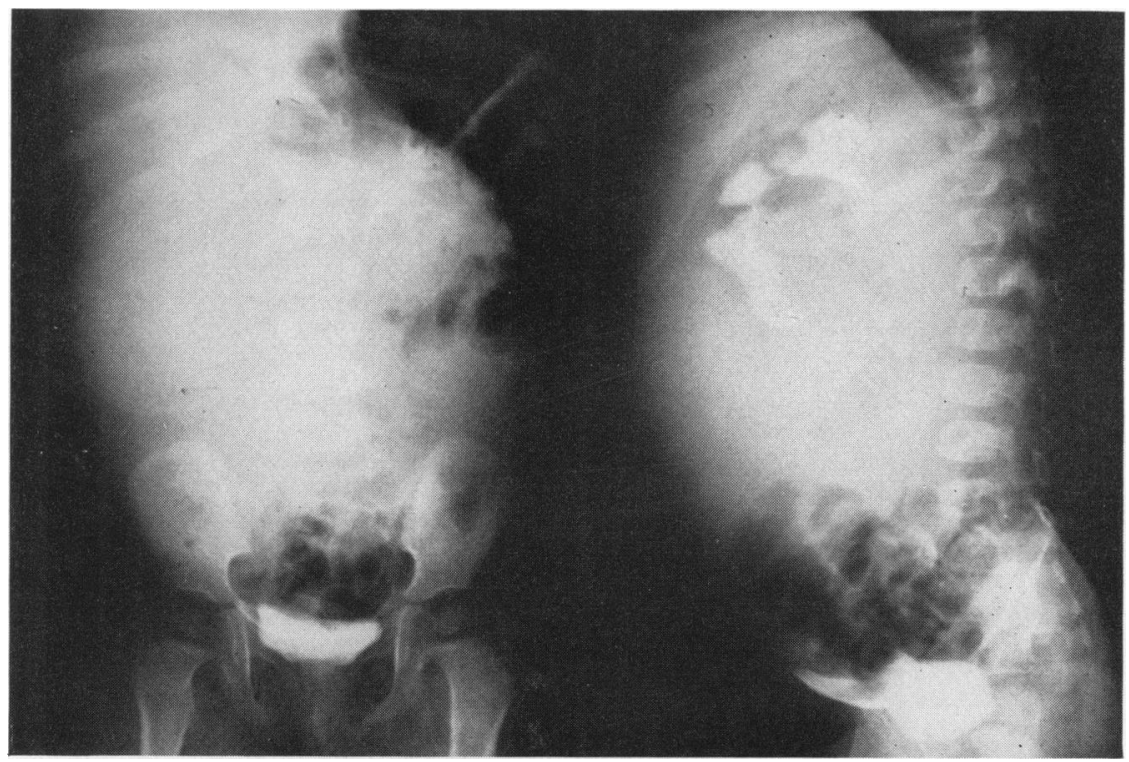

Fig. 9.-Case 9. Wilms' tumour. A-P view not helpful in making diagnosis; lateral film needed for differential diagnosis between Wilms' tumour and neuroblastoma. 


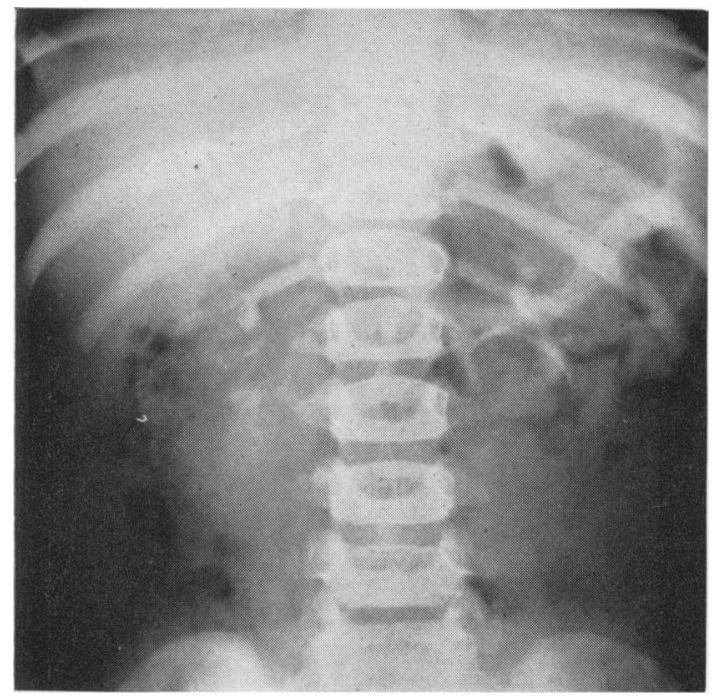

FIG. 10.-Case 10. Intravenous pyelogram showing crescentic displacement of calyx and pelvis on left due to a small Wilms' tumour. Compare with Fig. 11.

the renal pelvis. This proved to be a Wilms' tumour and the smallest one we have encountered clinically. The patient is alive and well four and a half years postoperatively. X-ray therapy was given.

Case 11. D.P. This 3-year-old girl with pyuria and fever was investigated for pyelonephritis by intravenous pyelography. In this study the same distortion of the left renal pelvis is noted as that seen in the previous patient's films. Note how the carbonated beverage has not only given better definition to the intravenous pyelography but has depressed the kidneys by intragastric gas pressure a distance of one vertebral body (Fig. 11).
Nephrectomy was carried out in this child and, to our great surprise, the distortion of the pelvis was by an anomalous pyramid. This is the first anomalous pyramid we have encountered and the second such X-ray picture in about 17,000 pyelograms. Obviously, this is not an adequate method of making a diagnosis of a small Wilms' tumour and on our next occasion we will resort to arteriography.

In summary, all the Wilms' tumours presented were asymptomatic. One such tumour was found on a routine physical examination by a paediatrician; another was found by a mother who claims it was not there the day before; a third was found when a local physician did a hurried physical examination before giving a prophylactic vaccine; a father discovered a fourth tumour and, finally, the fifth patient was thought to have a mass even when none could be palpated, but nevertheless proved to have the smallest clinical Wilms' tumour in our series.

Finally, to shake one's confidence in any diagnostic procedure, a normal kidney with an anomalous pyramid mimicked almost identically a Wilms' tumour.

None of these patients had haematuria, a sign which is usually interpreted as meaning a very poor prognosis because of early penetration of blood vessels. However, our own experience indicates that this might also be a very early sign and lead to a happy prognosis.

Although X-ray therapy is recommended as a routine post-operatively, patients are individually managed and when the tumour is small, the patient young, and the surgery atraumatic, no X-ray therapy is given.

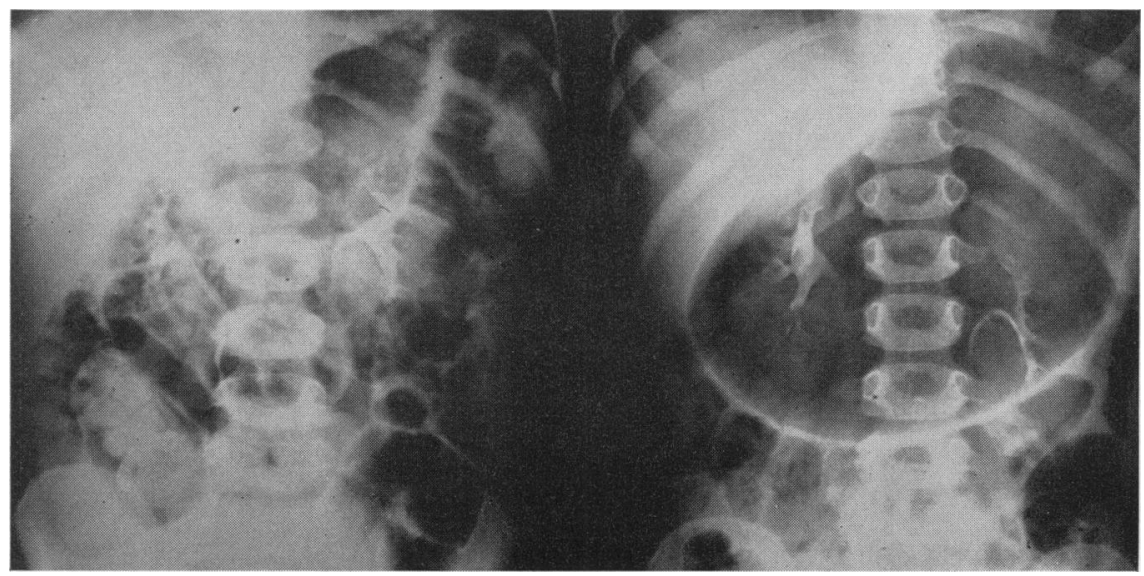

Fig. 11.-Case 11. Intravenous pyelogram showing crescentic displacement of calyx and pelvis on left due to an anomalous renal pyramid. Compare with Fig. 10. 
Before leaving malignant tumours, we should again remind ourselves of the rapid growth of these two just discussed and the fact that the usual behaviour of adult cancer is crowded into a much shorter time in the paediatric age group. What is thought of as a five-year cure can usually be telescoped into a 14-month period in reference to the two tumours just discussed.

As to their importance, they account for $20 \%$ of all malignant tumours in children and $40 \%$ of those against which we have at the moment a satisfactory weapon.

The following are some other abdominal tumours which occasionally present themselves for differential diagnosis.

Case 12. F.L. A $2 \frac{1}{2}$-year-old girl entered hospital because of an anaemia. The evacuation of some of the barium enema revealed an abnormal air-filled bowel in the right upper quadrant which, when we did the small bowel study, filled with barium. The patient was sent home but returned bleeding severely from the rectum and was operated upon. Her lesion proved to be an ulcerated duplication of the ileum (Fig. 12).

Case 13. R.S. was a $5 \frac{1}{2}$-month-old girl who at the age of 3 weeks was found to have a large liver. Nothing was done for this child until she came to our hospital at $5 \frac{1}{2}$ months when she was really a huge abdomen with a small baby attached. She was completely dehydrated from vomiting and could not hold anything in her stomach. A survey film revealed a huge abdominal mass on the right side thought to be liver. With some barium in the stomach the edge of the mass could be seen.

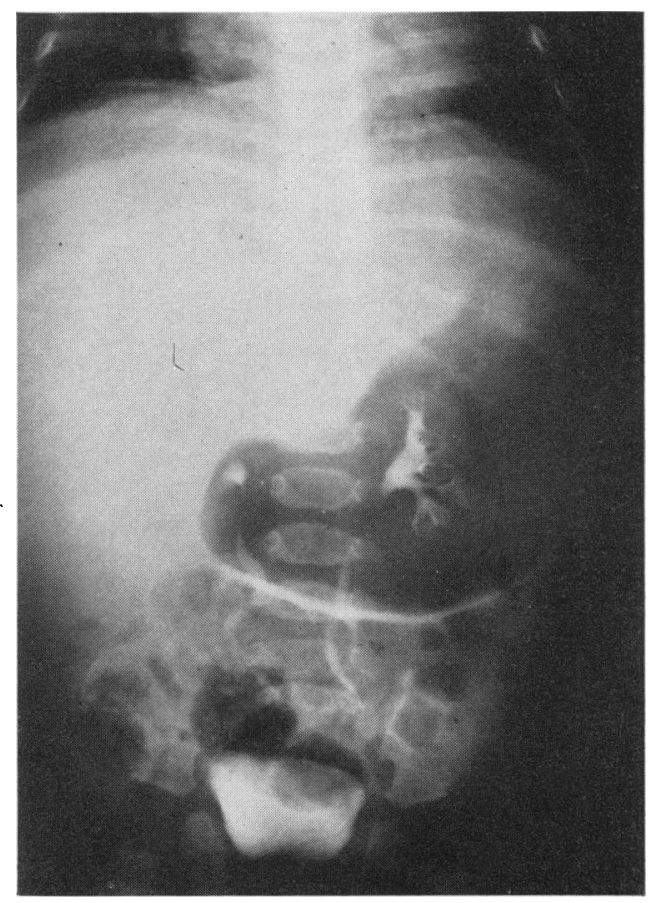

FIG. 13.-Case 13. Tumour of liver, affecting chiefly right lobe. Haemangioendothelioma.

An intravenous urogram proved that this was not intrinsic to the kidney (Fig. 13). At operation it was

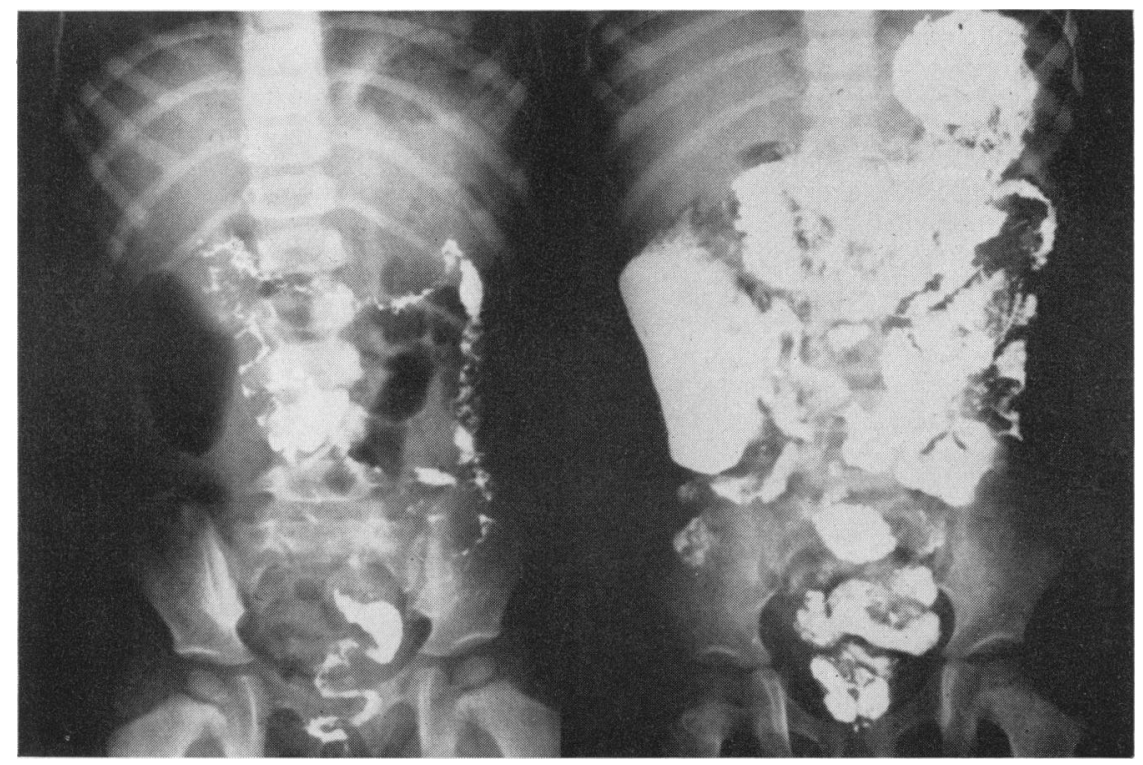

Fig. 12.-Case 12. Duplication of ileum. Film on left shows lesion outlined with gas, on right filled with barium. 


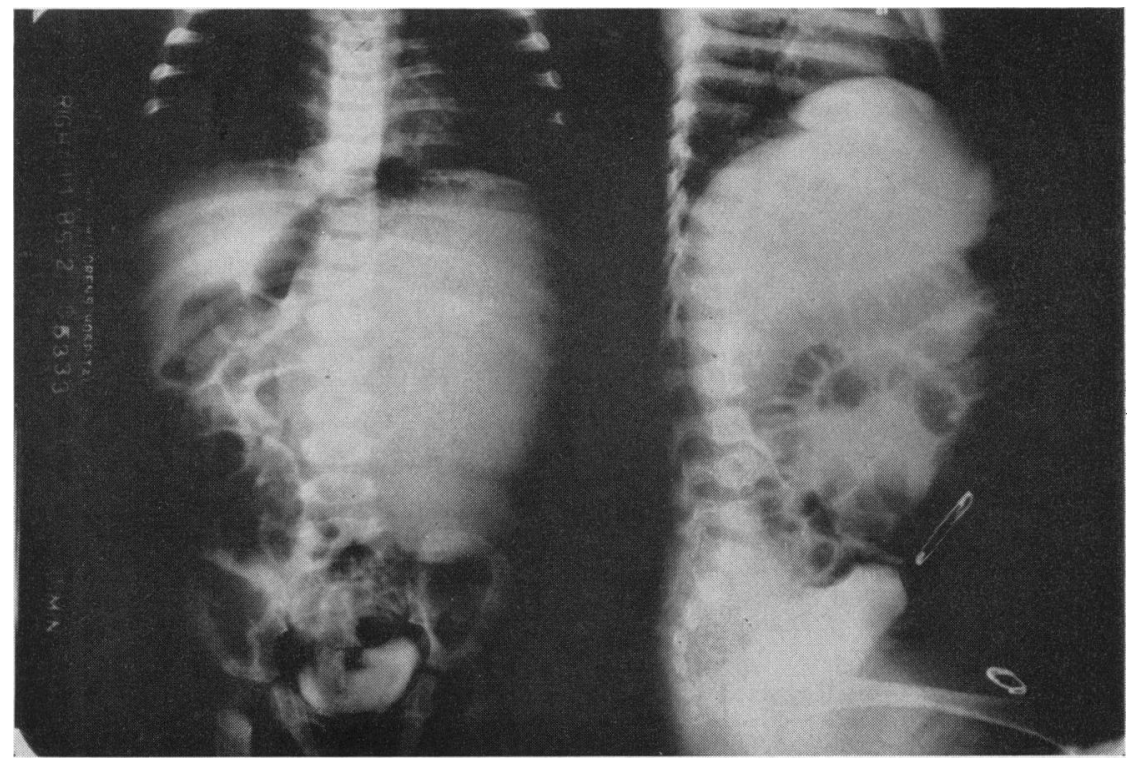

thought that we were dealing with a primary carcinoma of the liver but a piece taken for biopsy was reported as being a benign haemangio-endothelioma. The child received $1,000 \mathrm{R}$ tissue dose to the liver which had shrunk to normal size in eight months. The child is alive and well several years later.

Case 14. J.M. was a $2 \frac{1}{4}$-year-old boy with progressive enlargement of his abdomen of one month's duration. The flat film showed a huge mass and the intravenous pyelogram showed the kidney to be depressed so that a diagnosis of neuroblastoma was made (Fig. 14). At operation the tumour was found to be intrinsic to the liver and the mass seemed to involve both right and left lobes. The child was given 3,200 $\mathrm{R}$ tissue dose in 33 days through a portal $13 \times 15 \mathrm{~cm}$. Eight weeks after X-ray treatment the child was re-explored and the tumour was found to lie in the right lobe only. A right hepatic lobectomy was carried out and the child is alive and well five years post-operatively. The histological diagnosis was hepatoblastoma.

Case 15. N.L. This $4 \frac{1}{2}$-year-old girl had a six-week history of lower abdominal pain which eventually became epigastric. Three weeks before admission she became jaundiced and had clay-coloured stools. The gastrointestinal series of radiographs undertaken at another hospital showed a wide duodenal loop which would have suggested in an adult carcinoma of the head of the pancreas (Fig. 15). The child was operated upon in our institution five days after the study elsewhere and she did indeed have a tumour in the region of the head of the pancreas which proved on histological section to be a reticulum cell sarcoma. The tumour involved the coeliac axis and was not resectable. The child received $2,800 \mathrm{R}$ tissue dose over a portal of $15 \times 15 \mathrm{~cm}$. over a period of three weeks. She did well for a while but six months after operation she came into hospital in coma

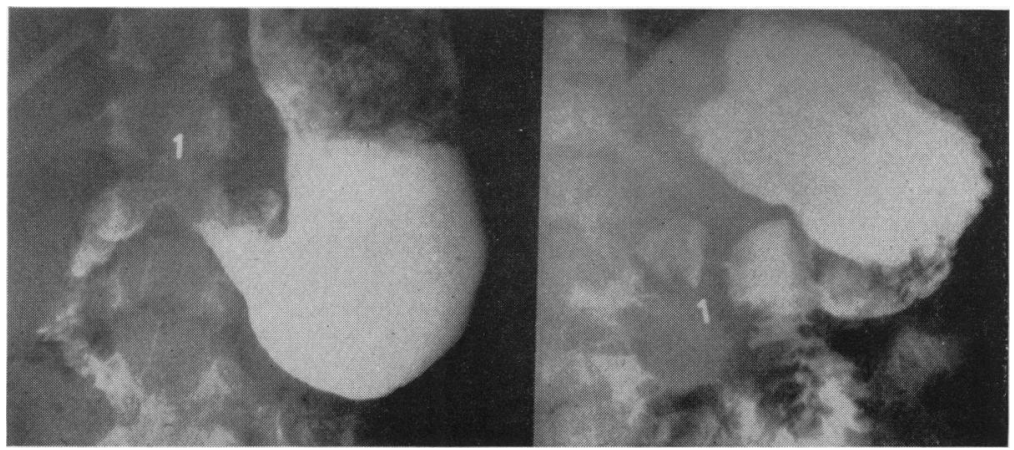

Fig. 15.-Case 15. Widening of duodenal loop caused by reticulum cell sarcoma simulating classical carcinoma of head of pancreas. 


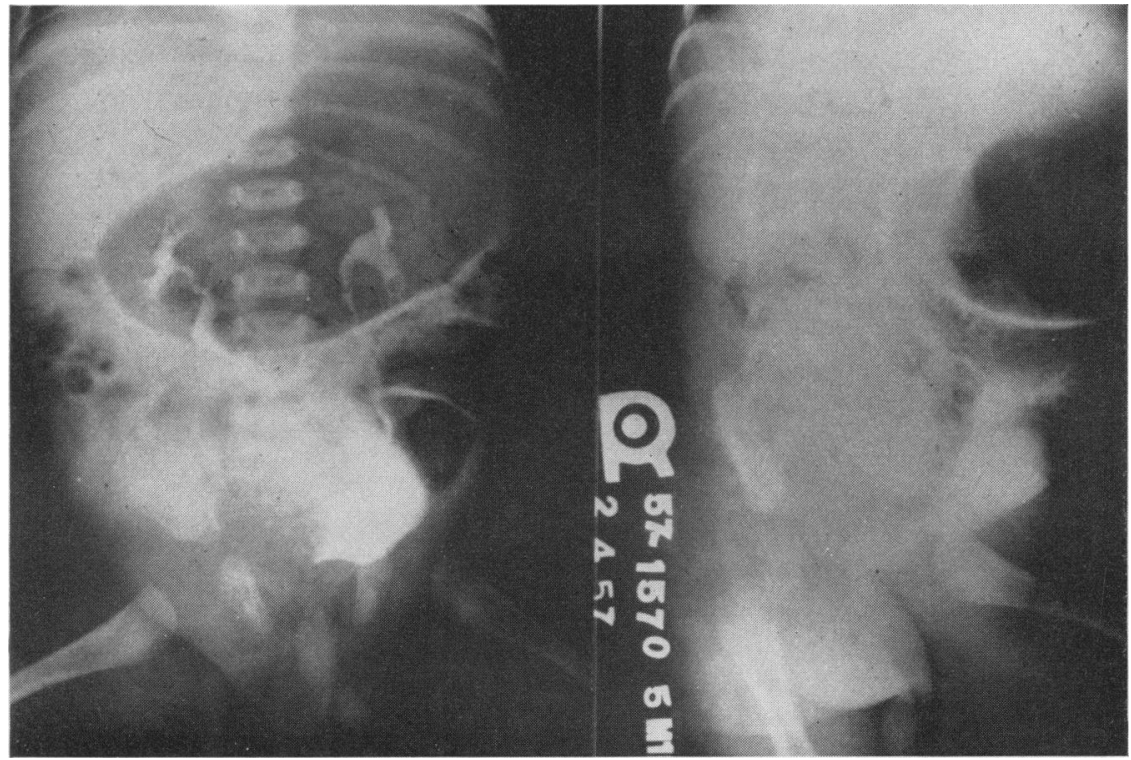

Fig. 16.-Case 16. A-P and lateral intravenous pyelogram for abdominal mass which proved to be iliac abscess secondary to an infected circumcision.

and died. At autopsy she was found to have radiation nephritis as the cause of her death.

Case 16. This 2-week-old boy had a swollen leg and prominent veins over the right lower quadrant. It was thought that this would be a neuroblastoma on the basis of clinical impression. It proved, however, to be a staphylococcal abscess secondary to a dirty circumcision and inguinal adenitis (Fig. 16).

Case 17. J.A. Eleven days before this examination this 6-year-old boy was struck in the epigastrium by the handlebars of a bicycle. From that time on he had upper abdominal pain and vomiting. His serum amylase was 1,500 units. Original films show the appearance of a mass in the vicinity of the pancreas which had not altered when repeated two weeks later (Fig. 17). The child was treated by judicious neglect and had no further difficulty.

Case 18. E.T. This 11-year-old boy complained of jaundice of one month's duration and loss of appetite. He entered the Children's Hospital of Philadelphia with a temperature of $105^{\circ} \mathrm{F}$. and abdominal pain; gastrointestinal series of radiographs showed his common bile duct to be large as indicated by the depression of the duodenum (Fig. 18). The child was operated upon and a huge gall bladder and dilated common duct were found. The duct was opened and there extruded a number of flimsy structures resembling nasal polyps. A T-tube was left in the common bile duct and a cholangiogram indicated dilatation of the entire intrahepatic biliary tree. The patient died two months after operation and at autopsy had a large abdominal tumour as well as metastases in the abdomen, pelvic bones and liver. This, of course, is the classical early and late picture of a rhabdomyosarcoma.

Case 19. C.B. was a 4-year-old female who was admitted to hospital because of abdominal pain of one week's duration. An abdominal mass could be palpated in the left upper quadrant separate from the left kidney. At operation this proved to be a teratoma which was almost a complete embryo with arm and leg buds. It was necessary to remove the left kidney and left adrenal gland in the course of the dissection (Fig. 19).

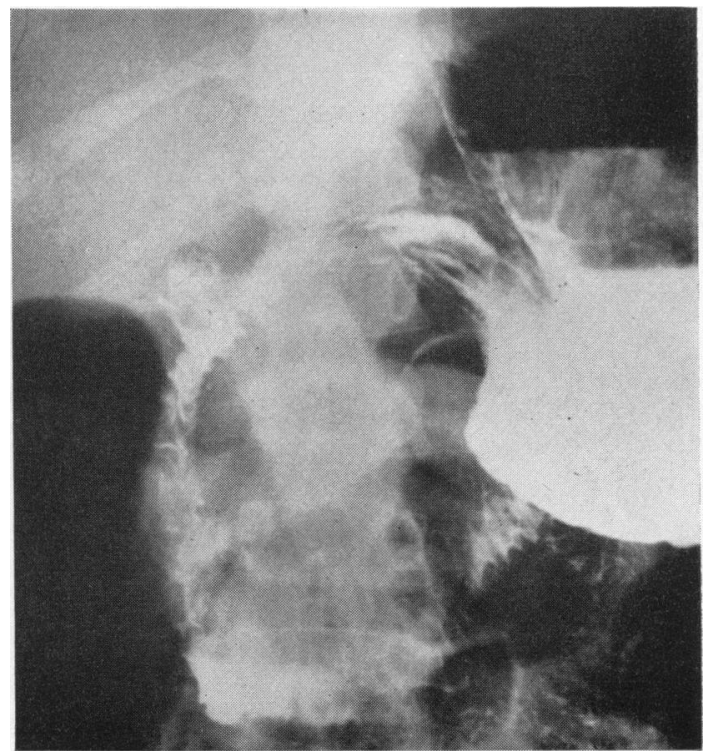

FIG. 17.-Case 17. Displacement of bowel caused by pseudocyst of pancreas 11 days after epigastric injury. 


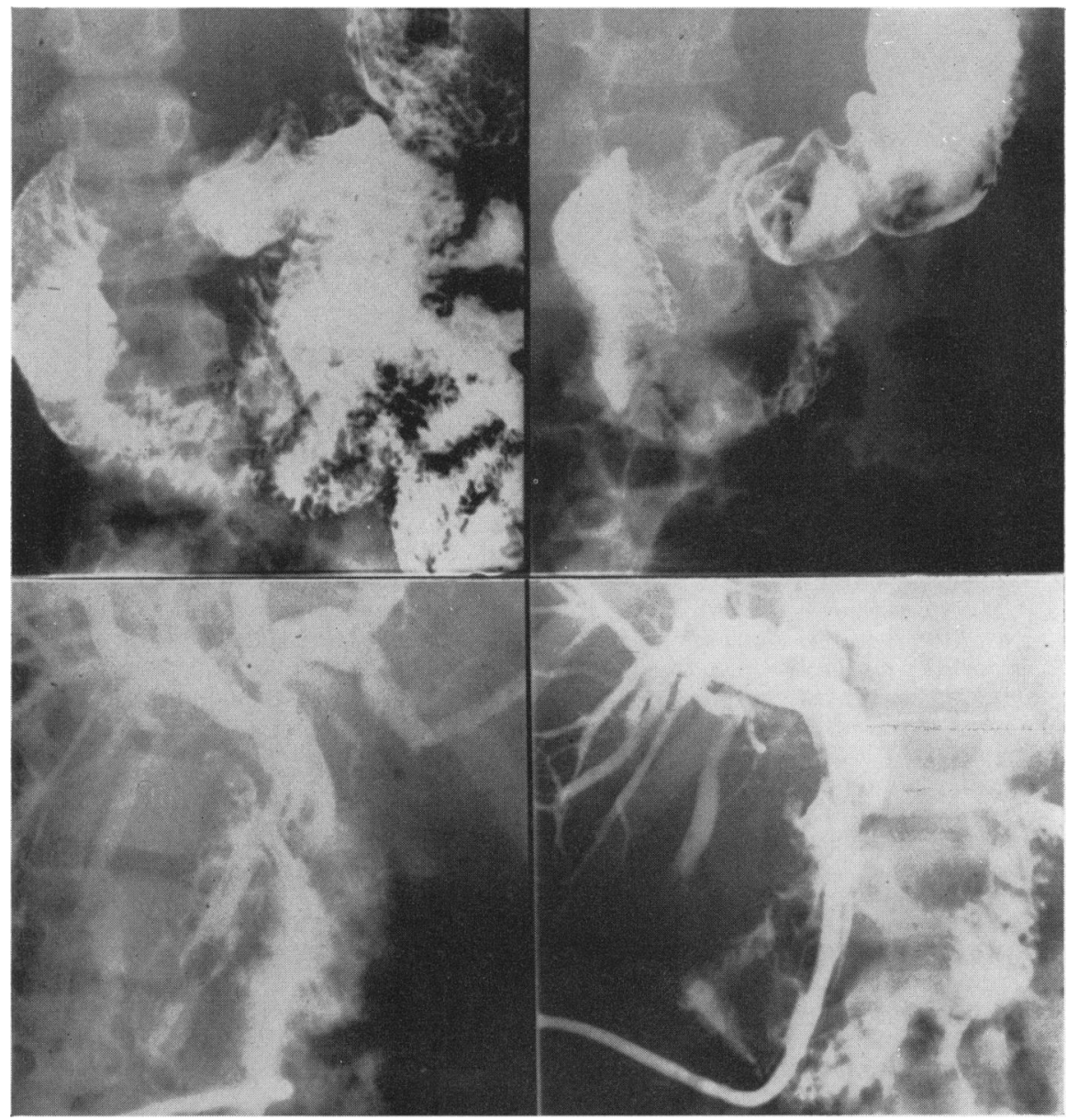

FIG. 18.-Case 18. Upper gastro-intestinal series showing interruption of barium shadow in duodenum due to an enlarged common bile duct. Cholangiogram shows dilatation of common bile duct and its proximal intrahepatic radicals. 

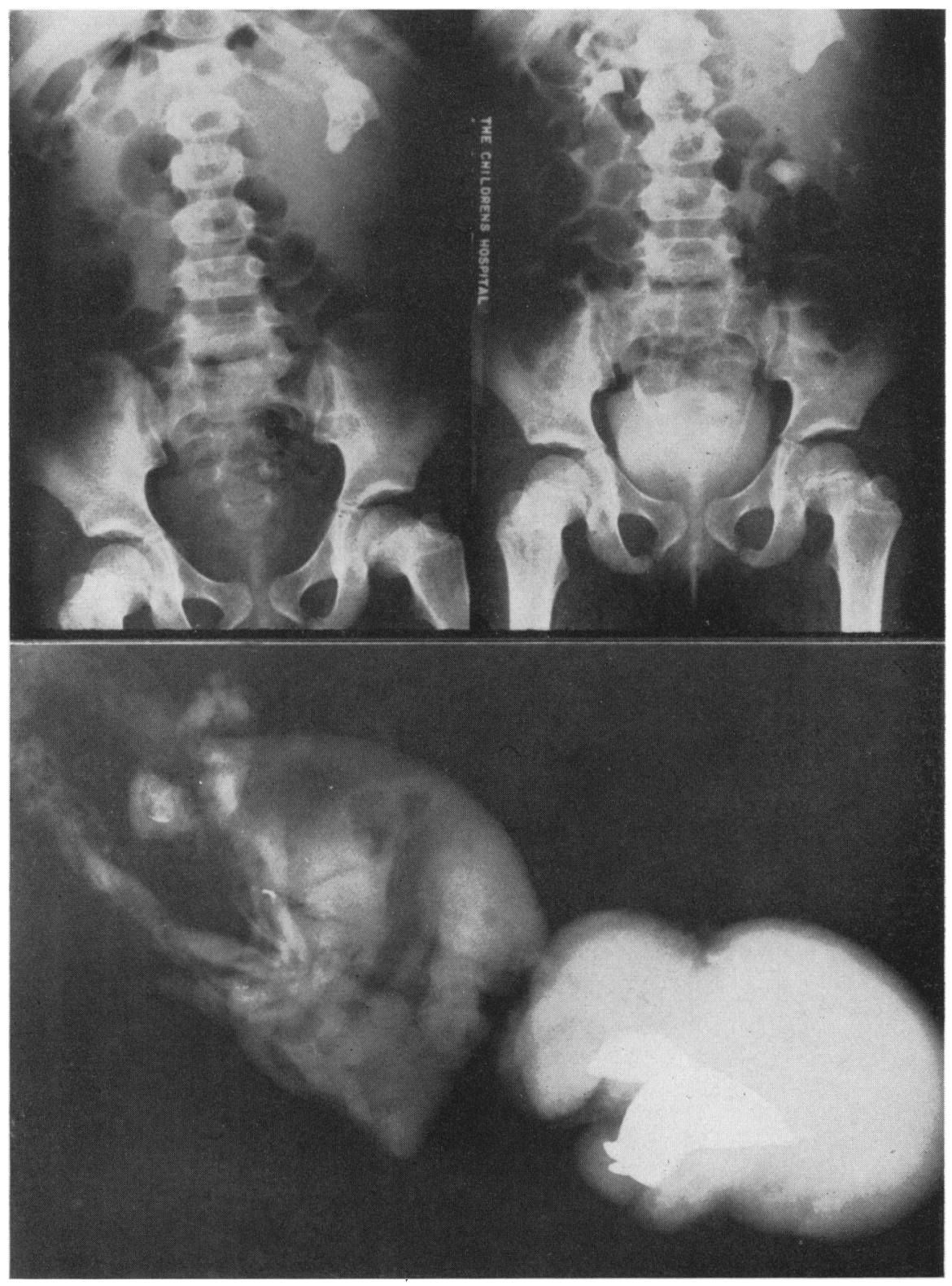

FIG. 19.-Case 19. Intra-abdominal teratoma attached to left kidney and adrenal gland, with X-ray of teratoma following extirpation. 


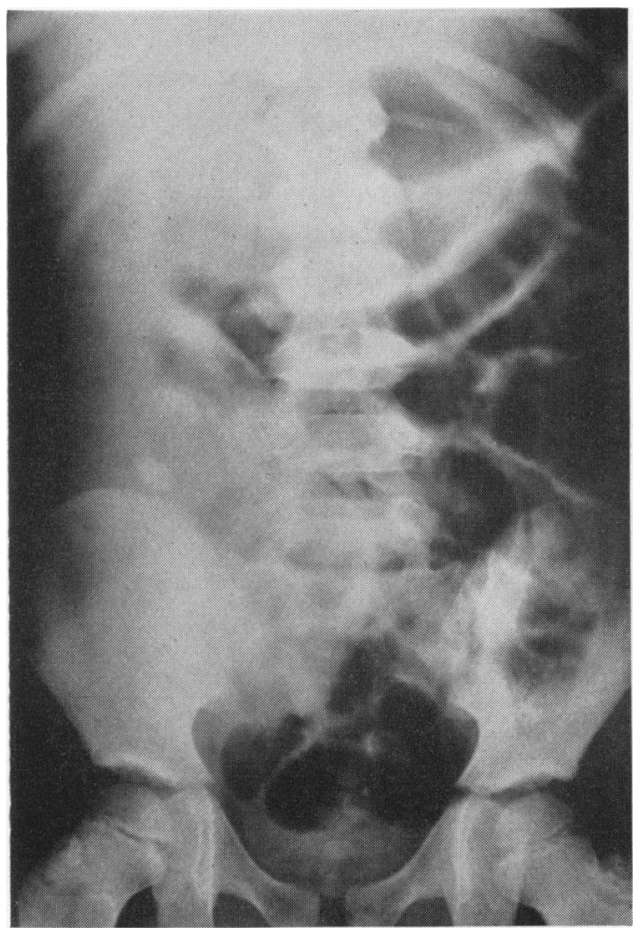

Fig. 20.-Case 20. Abdominal mass containing faecolith of calcific density; appendiceal abscess.
Case 20. D.P. was a $5 \frac{1}{2}$-year-old male with a two-week history of abdominal pain. In this two weeks the pain had become worse and the child had begun to vomit. At the time of examination there was severe abdominal tenderness and a mass could be palpated in the right lower quadrant. The films revealed a large soft tissue mass and a calcified mass within the large soft tissue density. This proved to be an appendiceal abscess with a faecolith (Fig. 20).

Case 21. T.E. A 6-month-old girl entered the hospital with a referring diagnosis of Wilms' tumour. On palpation of the abdomen there was a huge mass and, since palpation in the left upper quadrant moved the mass in the right upper quadrant and vice versa, the presumptive diagnosis was a Wilms' tumour in a horseshoe kidney. A flat plate of the abdomen revealed what looked like an old barium enema of the colon. Since there was no such history, it was presumed that the shadow represented calcifying faeces. A barium enema was carried out as a terminal aganglionic segment indicating megacolon was suspected. It was impossible to wash out the faecal impaction and at operation a colostomy was done. Six months later at the time of attempted pull-through procedure two lumina were noted in the bowel. It was then understood that we were dealing with a duplication of the colon. In the original films it was possible to see an air column streaking past the impaction of calcific density. The bowel was re-anastomosed after resecting the common wall between the two duplications (Figs. 21, 22, 23).

Case 22. L.S. This 3-year-old girl came into hospital because of pain in her left hip of one year's

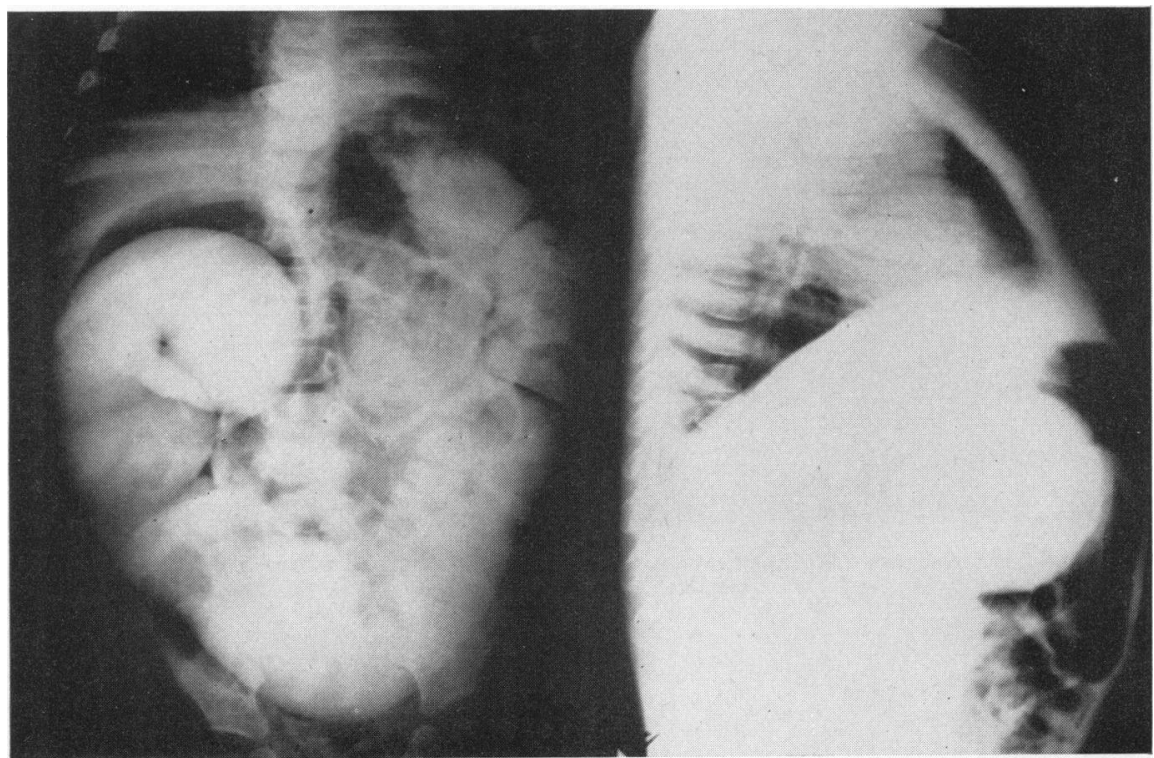

Fig. 21.-Case 21. Faeces of calcific density in duplication of colon with blind distal end. 


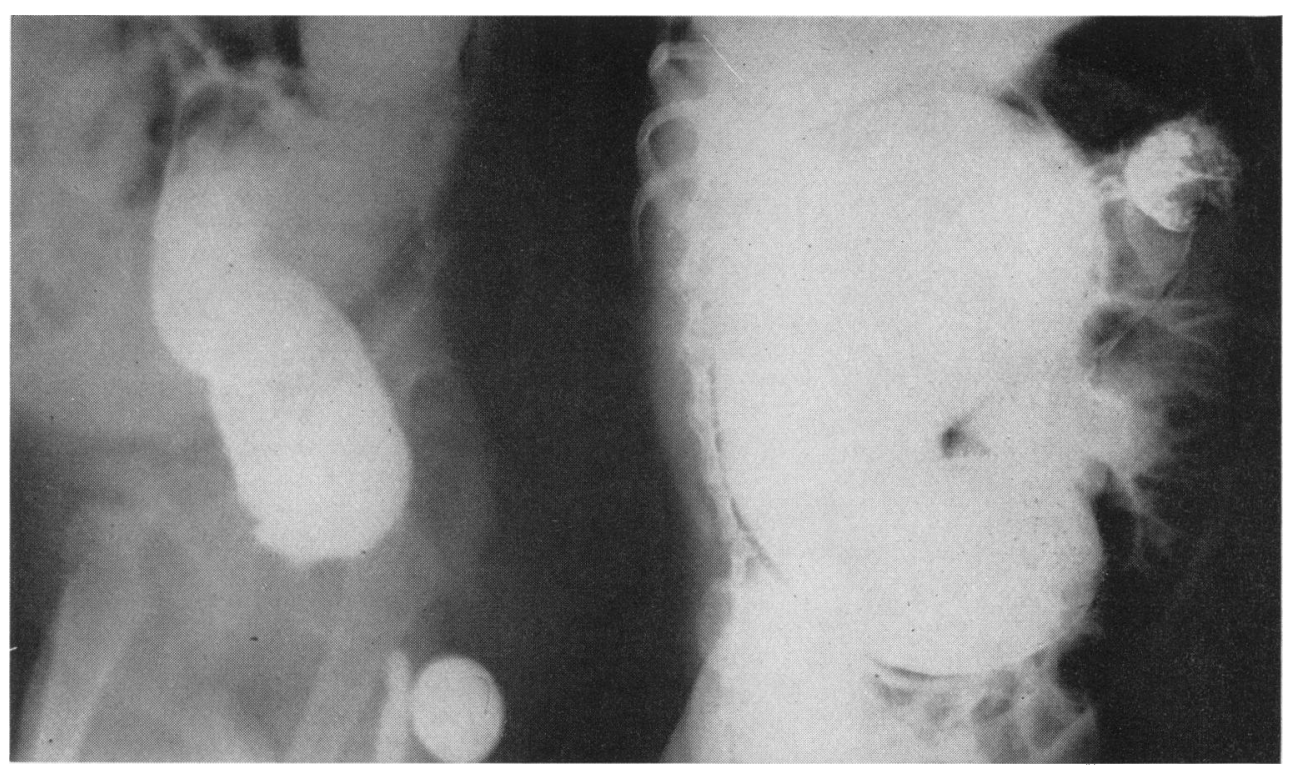

FIG. 22.-Case 21. Barium enema of patient in Fig. 21. Note air column to left in lateral film indicative of true colon.

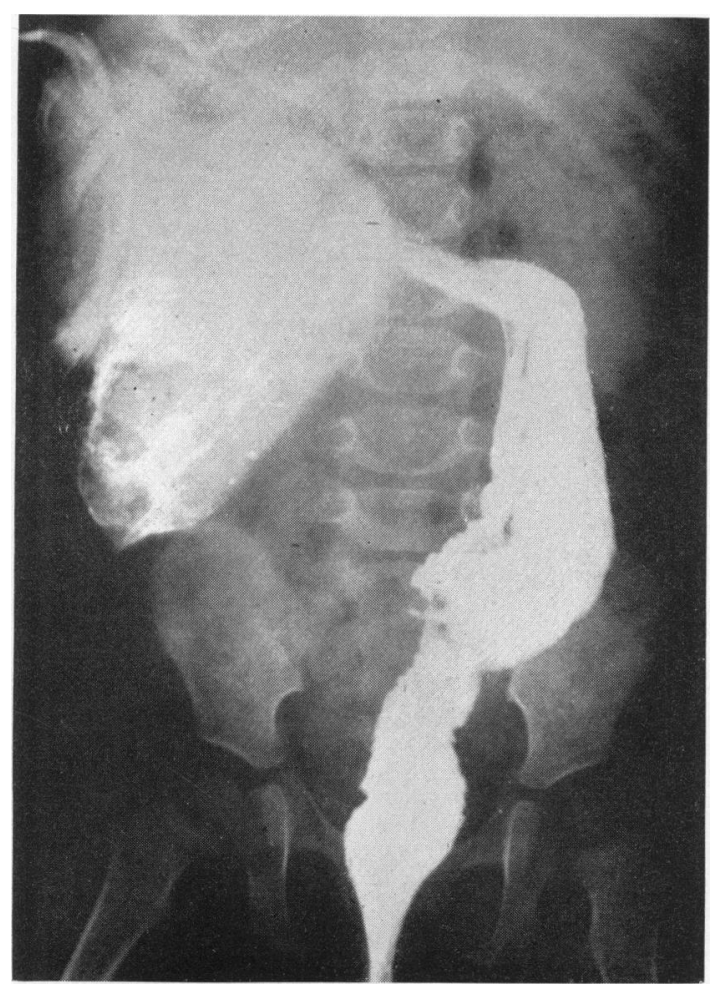

Fig. 23.-Case 21. Post-operative barium enema showing duplication proximally and single lumen distally. 


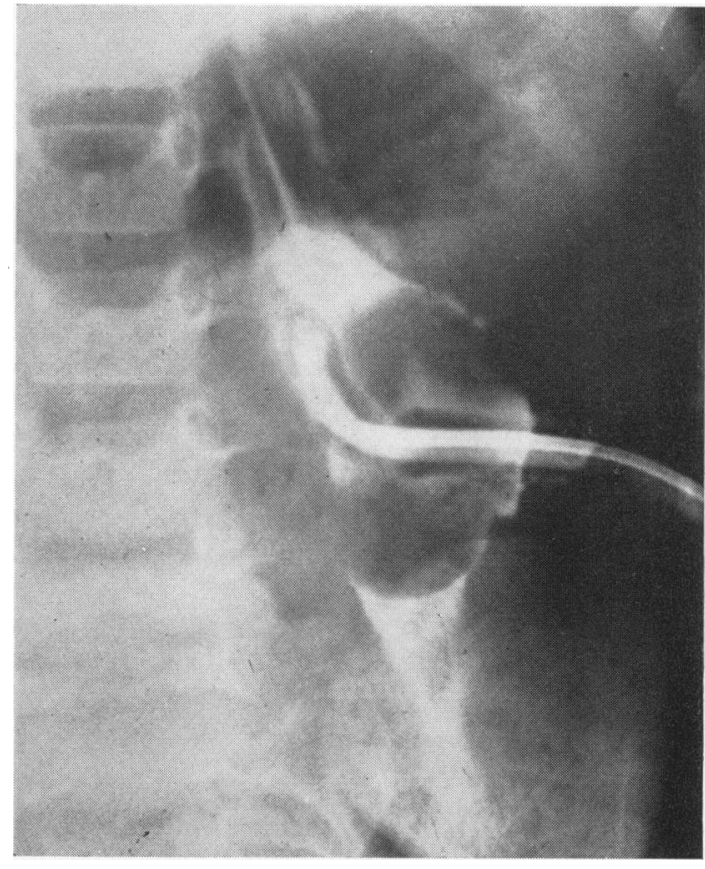

FIG. 24.-Case 22. Post-operative film showing catheter in retroperitoneal cavity communicating with duplication of stomach (neurenteric cyst?). duration. She had been studied in several hospitals for this period of time. The films of her pelvis were normal but a mass lesion was found in the left mid-abdomen which seemed to be extrinsic to the left kidney. At operation there was a retroperitoneal mass lying beneath the mesentery of the colon. On aspiration this produced thick material resembling motor oil which was evacuated. It was then obvious that an hour-glass constriction connected this sausage-shaped mass with a much larger mass which lay within the psoas muscle. This latter mass also contained the same thick grumous material.

Further dissection revealed that the initial mass was a cystic structure with a lining somewhat resembling that of the stomach. It perforated posteriorly into a pseudocyst of the psoas muscle. Microscopical sections revealed gastric mucosa. This was a duplication of the stomach without attachment to any other intestinal viscus (Fig. 24). In all likelihood with further dissection this lesion could have been proved to be a neurenteric cyst.

One could continue to discuss abdominal tumours for a considerable period of time, calling upon experience with the commonplace as well as the bizarre. I trust these few examples of abdominal masses have served to place in proper focus the more serious and challenging aspect of the management of abdominal tumours in children, namely those malignant lesions which carry such a forbidding mortality. 